\title{
Nápojový primmgsl
}

\section{Stanovenie chinínu a kofeínu v nealkoholických nápojoch}

Doc. Ing. ALEXANDER PRÍBELA, CSc., Katedra chémie a technológie sacharidov a potravín CHTF, Bratislava Ing. KAROL TOMĀŠEK, CSc., Pivovary a sladovne, GRT, Bratislava

Ing. BOŽENA MEDOVARSKĀ, Výskumný ústav pôdoznalecký a výživy rastlín, Bratislava

Výroba nealkoholických nápojov za posledné roky enormne vzrástla a má stále stúpajúcu tendeciu. Príčinou tohto stavu je najmä zhoršujúca sa akost pitnej vody, rozvoj motorizmu a s ním súvisiaci zákaz požívania alkoholických nápojov šoférmi. Aj výživové a dietetické hradiská tu zohrávajú určitú úlohu, pretože mnohé nealkoholické nápoje predstavujú aj nezanedbatelný príjem dôležitých nutričných a senzorických zložiek (vitaminy, minerálne soli, aromatické a chut podporujúce látky). Osobitnú skupinu tvoria nealkoholické nápoje obsahujúce psychicko-stimulatívne zložky najmä alkaloidy, heteroglykozidy, prípadne iné senzoricky aktívne zložky. $\mathrm{Z}$ tejto skupiny najväčší trend spotreby zaznamenávajú nealkoholické nápoje na báze chinínu, kofeínu ( $v$ menšej miere tiež teobromínu), ktoré majú aj špecifické farmakodynamické účinky na ludský organizmus. Tieto zložky sú preto predmetom záujmu kontroly hygienických, ale i výrobných orgánov $[1,2]$.

Pri výbere metód pre stanovenie uvedených látok treba sa riadit druhom vzorky, požiadavkami na presnost, citlivostou, časovou a technickou náročnostou. $\mathrm{Z}$ praktického hradiska sú výhodné také stanovenia, ktoré nevyžadujú zdíhavé čistiace a rozdelovacie techniky a pritom poskytujú dostatočne presné a spolahlivé výsledky.

Na stanovenie chinínu boli vypracované početné metódy založené na spektrálnych princípoch najmä meraní fluorescencie [3-4] a absorbancie v UV-oblasti [5-7]. Špecifičnost týchto metod je odvislá od množstva interferujúcich látok vo vzorke. Spektrofotometrické a fluorimetrické merania sú vhodné pre čisté roztoky, nealkoholické nápoje typu Chito, zatial čo pre nápoje z prirodzených extraktov je priame stanovenie zatažené značnými chybami. V takýchto prípadoch sa bư použijú špeciálne čistiace operácie (napr. extrakcia chloroformom $z$ alkalického prostredia) alebo rozdelovacie techniky, najmä chromatografia na tenkej vrstve, stípcová chromatografia na silikagéli apod. $[8,9]$. Rozdelené chromatogramy sa vyhodnotia buđ denzitometricky priamo na tenkých vrstvách, alebo po vyeluovaní škvín. Na fluorimetrické stanovenie vplýva obsah chloridov a železa vo vzorke, pretože tieto látky zhášajú fluorescenciu chinínu v závislosti od ich množstva. Prí niektorých metódach rušivo pôsobí aj kysličník uhličitý, a preto sa musí pred stanovením odstránit $[2,5]$. V poslednom čase bola rozpracovaná metóda plynovej chromatografie s vysokým stupňom automatizácie a vyhodnocovania výsledkov. Stanovenie touto technikou je špecifické a velmi citlivé [10, 11].

Na stanovenie kofeínu bolo vypracovaných tiež množstvo metód, ktoré využívajú absorbanciu v UV svetle $[12,16]$, fotometriu reakčného produktu kofeínu $s$ kyselinou fosfomolybdenovou alebo s kyselinou malónovou $[17,18]$. Titračné metody stanovenia kofeínu vychádzajú $\mathrm{z}$ chloroformových extraktov vzoriek alkalizovaných amoniakom. Kofeín sa po vykryštalizovaní titruje kyselinou chloristou [21]. Rovnako možno stanovit kofeín po vyzrážaní jódom spätnou titráciou tiosíranom sodným [22]. Pri stanovení kofeínu spektrofotometricky je obsah interferujících látok (fenolické látky, triesloviny, produkty Maillardových reakcií] ovela výraznejší než pri stanovení chinínu. Preto spravidla vždy, ak sa majú dosiahnut exaktnejšie výsledky, musí sa vzorka čistif cez stípec polyamidu (nečistoty sa absorbujú a kofeín prechádza do eluátu) alebo chromatografiou na tenkej vrstve $[15,16,20,23]$. Výsledky sa vyhodnocujú priamo dezitometricky pri $272 \mathrm{~nm}$ [24]. Na stanovenie kofeínu bola vypracovaná tiež metóda plynovej chromatografie $[10,25]$.

Zriedkavejšie sa sleduje obsah teobromínu v nealkoholických nápojoch, ako sprievodný alkaloid vedla kofeínu. Takmer pri všetkých metódach na stanovenie teobromínu sa využívajú deliace metódy spojené so spektrofotometrickou indikáciou $[13,17,26]$. Na oddelenie teobromínu a teofylínu je vypracovaná chromatografia na tenkej vrstve silikagélu s následným spektrofotometrickým stanovením pri $276 \mathrm{~nm}$ [27].

\section{Experimentálna čast'}

V experimentálnej práci sme sa zamerali na preskúšanie a matematicko-štatistické zhodnotenie metod, na stanovenie kofeínu, chinínu a teobromínu.

Na stanovenie chinínu sme použili štyri metódy, ktoré sa ukázali metodicky a časove nenáročné, vhodné najmä na rutinné použitie $\mathrm{v}$ nápojárskom priemysle. Išlo o fluorimetrické stanovenie chinínu podra Stacheho metody popísanej a modifikovanej Nuijensom a Veldenom [3]. Táto metóda je navrhnutá v ČSN 560240 [17]. Dalej dve spektrofotometrické metódy. Prvá podra Heya s extrakciou chinínu do chloroformu [7] a druhá podra Gilsa a Hidskesa, kde sa priamo stanovuje absorbancia pri $347,5 \mathrm{~mm}$ [5]. Konečne titračná metóda s kyselinou chloristou po predchádzajúcej extrakcii s chloroformom [21].

Na stanovenie kofeínu a teobromínu sme preskúšali tri metódy, $z$ toho dve na stanovenie len kofeínu (fotometrickú a titračnú metódu) a vážkovú metódu na stanovenie kofeínu a teobromínu popri sebe. Ako vzorky sme použili rôzne nealkoholické nápoje s obsahom chinínu a kofeínu, kávu a štandardné látky.

\section{Výsledky a diskusia}

Hodnoty v tab. 1 ukazujú štatistické údaje obsahu chinínu v nealkoholických nápojoch. Porovnaním vychádza, že relatívne najpresnejšie výsledky dáva spektrofotometrická metóda s extrakciou chinínu, kde miery presnosti na $5 \%$ hladine významnosti $[95 \%]$ sú 1,4 až $3,7 \%$, recovery test $98,9-99,0 \%$. Podobne presné vysledky poskytuje fluorimetrická metóda $s$ mierou presnosti $1,1-4,4 \%$ a recovery testom $99,9 \%$.

Titračná metóda poskytuje rovnomerný rozptyl vysledkov s presnostou 3 až $3,8 \%$. Relatívne najhoršie 
Tabulka 1. Štatistické údaje metód na stanovenie chininu

\begin{tabular}{|c|c|c|c|c|c|c|c|}
\hline Vzorka & $n$ & $\bar{x}$ & $R$ & $s$ & $M^{\prime}(\%)$ & \multicolumn{2}{|c|}{$\operatorname{Rec} .(\%)$} \\
\hline \multicolumn{8}{|c|}{ A. Fluorimetrická metóda } \\
\hline $\begin{array}{l}\text { Chito } \\
\text { Chito Tonic } \\
\text { Mirinda Tonic } \\
\text { Koral Tonic } \\
\text { Štandard } \\
\text { Štandard }\end{array}$ & $\begin{array}{l}5 \\
5 \\
5 \\
5 \\
8 \\
8\end{array}$ & $\begin{array}{l}15,39 \\
29,56 \\
37,76 \\
48,66 \\
19,91 \\
19,99\end{array}$ & $\begin{array}{l}0,793 \\
0,867 \\
0,900 \\
0,866 \\
1,100 \\
0,300\end{array}$ & $\begin{array}{l}0,341 \\
0,373 \\
0,387 \\
0,372 \\
0,370 \\
0,105\end{array}$ & $\begin{array}{l}4,4 \\
2,5 \\
2,1 \\
1,5 \\
3,7 \\
1,1\end{array}$ & $\begin{array}{l}\overline{ } \\
\overline{20} \\
20\end{array}$ & $\begin{array}{l}\overline{-} \\
\bar{z} \\
\overline{99,8} \\
99,9\end{array}$ \\
\hline \multicolumn{8}{|c|}{ B. Spetrofotometrická metóda s extrakciou } \\
\hline $\begin{array}{l}\text { Chito } \\
\text { Chito Tonic } \\
\text { Mirinda Tonie } \\
\text { Koral Tonic } \\
\text { Standard } \\
\text { Standard } \\
\text { Standard }\end{array}$ & $\begin{array}{l}5 \\
5 \\
5 \\
5 \\
5 \\
5 \\
5\end{array}$ & $\begin{array}{l}15,29 \\
28,44 \\
37,48 \\
50,11 \\
19,77 \\
39,59 \\
18,96\end{array}$ & $\begin{array}{l}0,666 \\
0,466 \\
0,730 \\
1,499 \\
0,400 \\
0,756 \\
0,750\end{array}$ & $\begin{array}{l}0,286 \\
0,200 \\
0,314 \\
0,623 \\
0,172 \\
0,325 \\
0,263\end{array}$ & $\begin{array}{l}3,7 \\
1,4 \\
1,7 \\
2,5 \\
1,7 \\
1,6 \\
2,8\end{array}$ & $\begin{array}{l}\bar{z} \\
\bar{z} \\
20 \\
40 \\
19,2\end{array}$ & $\begin{array}{l}\bar{Z} \\
\bar{Z} \\
\overline{98,9} \\
99,0 \\
98,9\end{array}$ \\
\hline \multicolumn{8}{|c|}{ C. Spetrofotometrická metóda bez extrakcie (rýchlometóda) } \\
\hline $\begin{array}{l}\text { Chito } \\
\text { Chito Tonic } \\
\text { Chito Tonic } \\
\text { Chito Tonic } \\
\text { Mirinda Tonic } \\
\text { Koral Tonic } \\
\text { Chito Tonic } \\
\text { št. prídavok } \\
\text { Chito št. prídavok } \\
\text { Sttandard } \\
\text { Ștandard } \\
\text { Standard }\end{array}$ & $\begin{array}{r}6 \\
6 \\
10 \\
10 \\
10\end{array}$ & \begin{tabular}{r|}
16,90 \\
37,20 \\
42,75 \\
40,51 \\
50,95 \\
52,70 \\
1,92 \\
1,93 \\
13,6 \\
22,0 \\
29,8
\end{tabular} & $\begin{array}{l}1,500 \\
2,000 \\
0,510 \\
1,950 \\
1,200 \\
0,900\end{array}$ & $\begin{array}{l}0,597 \\
0,860 \\
0,219 \\
0,510 \\
0,516 \\
0,387 \\
0,350 \\
0,106 \\
0,552 \\
0,487 \\
1,040\end{array}$ & $\begin{array}{r}7,0 \\
4,6 \\
1,0 \\
2,5 \\
2,0 \\
1,5 \\
36,5 \\
11,0 \\
8,1 \\
4,4 \\
7,0\end{array}$ & 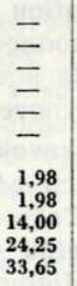 & $\begin{array}{l}= \\
= \\
= \\
= \\
96,9 \\
97,6 \\
95,8 \\
94,0 \\
89,0\end{array}$ \\
\hline \multicolumn{8}{|c|}{ D. Titračná metóda } \\
\hline $\begin{array}{l}\text { Chito } \\
\text { Chito Tonic } \\
\text { Mirinda Tonic } \\
\text { Koral Tonic }\end{array}$ & $\begin{array}{l}5 \\
5 \\
5 \\
5\end{array}$ & $\begin{array}{l}15,51 \\
29,39 \\
37,68 \\
49,12\end{array}$ & $\begin{array}{l}0,648 \\
1,040 \\
1,656 \\
1,944\end{array}$ & $\begin{array}{l}0,279 \\
0,447 \\
0,715 \\
0,836\end{array}$ & $\begin{array}{l}3,6 \\
3,0 \\
3,8 \\
3,4\end{array}$ & $\bar{z}$ & $\bar{z}$ \\
\hline
\end{tabular}

výsledky dáva spektrofotometrická rýchlometóda, kde miera presností kolíše 1,5 až $8,1 \%$ a pri nízkých štandardných prídavkoch až $36 \%$. Spolahlivost vyjadrená recovery testom je 89 až $97,6 \%$.

Ak zrovnávame jednotlivé vzorky analyzované všetkými metódami (tab. 2), vidíme, že rýchlometóda dáva vyššie výsledky než ostatné tri metódy, čo len potvrdzuje, že obsah interferujúcich látok pri priamej spektrofotometrii je štatisticky významný a nemožno ho zanedbat.

Vplyv $\mathrm{CO}_{2}$ na výslednú hodnotu chinínu sme sledovali pri spektrofotometrickej a fluorimetrickej metóde. Zatial čo pri prvej metóde je vplyv $\mathrm{CO}_{2}$ zanedbatelný, pri druhej je velmi dôležité dôkladne vzorku dekarbonizovat, pretože hodnoty môžu byt o 2 až $4 \%$ vyššie ako vo vzorke s nedokonale odstráneným $\mathrm{CO}_{2}$. Pri spektrofotometrickej metóde je dôležitá aj extrakcia chinínu. Ak sme extrakciu opakovali 4 krát oproti trojnásobnej, ako sa uvádza v metode, zvy̌šil sa obsah o 0,4 až $6,4 \%$ [28].

Výsledky preskúšaných metód na stanovenie kofeinu a teobromínu sú zhrnuté do $t a b$. 3 . Z nich vyplýva, že uvedené metódy poskytujú menej presné výsledky ako pri stanovení chinínu. Miera presnosti sa pri titračnej metóde pohybuje od 4,9 do $5,9 \%$ a pri fotometrickej metóde od 5,3 do $17,2 \%$.

Recovery test pri fotometrickej metóde je pomerne nízky - 93,0\%. Zpätné stanovenie teobromínu pri vážkovej metóde je $97,5 \%$. Presnost gravimetrickej metódy na stanovenie teobromínu vedra kofeínu je pomerne nízka.
Tabutka 2. Porovnanie výsledkov stanovení chinínu rôznymi metódami

\begin{tabular}{|c|c|c|c|c|c|}
\hline Vzorka & $n$ & $\begin{array}{l}\text { Fluorimet- } \\
\text { rická met6- } \\
\text { da }(\mathrm{mg} / \mathrm{I})\end{array}$ & $\begin{array}{c}\text { Extrakčná } \\
\text { spektrofoto- } \\
\text { metrická me- } \\
\text { tóda } \\
(\mathrm{mg} / \mathrm{l})\end{array}$ & $\begin{array}{l}\text { Spektrofoto- } \\
\text { metrická me- } \\
\text { tóda (mg/) }\end{array}$ & $\begin{array}{c}\text { Extrakěná } \\
\text { titračnáa } \\
\text { metóda } \\
\text { (mg/l) }\end{array}$ \\
\hline Chito & $\begin{array}{l}1 \\
2 \\
3 \\
4 \\
5\end{array}$ & $\begin{array}{l}14,0 \\
15,8 \\
15,4 \\
15,4 \\
15,3\end{array}$ & $\begin{array}{l}15,7 \\
15,2 \\
15,3 \\
15,3 \\
15,0\end{array}$ & $\begin{array}{l}26,8 \\
27,6 \\
26,8 \\
27,6 \\
26,4\end{array}$ & $\begin{array}{l}15,2 \\
15,9 \\
15,5 \\
15,6 \\
15,4\end{array}$ \\
\hline Chito Tonic & $\begin{array}{l}1 \\
2 \\
3 \\
4 \\
5\end{array}$ & $\begin{array}{l}29,9 \\
29,3 \\
29,8 \\
29,8 \\
29,0\end{array}$ & $\begin{array}{l}28,3 \\
28,6 \\
27,2 \\
28,4 \\
28,6\end{array}$ & $\begin{array}{l}38,0 \\
37,2 \\
36,8 \\
38,0 \\
36,0\end{array}$ & $\begin{array}{l}29,3 \\
28,9 \\
29,9 \\
29,2 \\
29,7\end{array}$ \\
\hline Mirinda Tonic & $\begin{array}{l}1 \\
2 \\
3 \\
4 \\
5\end{array}$ & $\begin{array}{l}37,5 \\
37,5 \\
37,9 \\
38,4 \\
37,5\end{array}$ & $\begin{array}{l}37,6 \\
38,3 \\
37,6 \\
38,0 \\
38,0\end{array}$ & $\begin{array}{l}51,2 \\
51,2 \\
50,0 \\
51,2 \\
51,2\end{array}$ & $\begin{array}{l}39,9 \\
38,6 \\
37,9 \\
37,2 \\
37,7\end{array}$ \\
\hline Koral Tonic & $\begin{array}{l}1 \\
2 \\
3 \\
4 \\
5\end{array}$ & $\begin{array}{l}48,1 \\
49,7 \\
48,8 \\
48,9 \\
48,8\end{array}$ & $\begin{array}{l}50,0 \\
50,3 \\
49,4 \\
50,6 \\
50,1\end{array}$ & $\begin{array}{l}52,4 \\
52,4 \\
53,2 \\
53,2 \\
52,3\end{array}$ & $\begin{array}{l}50,2 \\
49,2 \\
48,3 \\
49,2 \\
48,6\end{array}$ \\
\hline
\end{tabular}

Tabulka 3. Štatistické údaje metod na stanovenie kofeinu a teobrominu

\begin{tabular}{|c|c|c|c|c|c|c|c|}
\hline Vzorka & $n$ & $\bar{x}$ & $\boldsymbol{R}$ & $s$ & $M^{\prime}(\%)$ & \multicolumn{2}{|c|}{ Rec. $(\%)$} \\
\hline \multicolumn{8}{|c|}{ A. Fotometrická metóda - kofeín } \\
\hline $\begin{array}{l}\text { Kofola } \\
\text { Kofola } \\
\text { Slovkola } \\
\text { Coca-cola } \\
\text { Pepsi-cola } \\
\text { Pepsi-cola } \\
\text { Standard } \\
\text { Standard }\end{array}$ & $\begin{array}{l}5 \\
5 \\
5 \\
5 \\
5 \\
5 \\
8 \\
8 \\
5\end{array}$ & \begin{tabular}{|r|}
62,22 \\
65,44 \\
96,38 \\
111,50 \\
51,50 \\
65,31 \\
93,44 \\
18,49
\end{tabular} & $\begin{array}{r}8,470 \\
12,640 \\
7,700 \\
19,250 \\
10,300 \\
10,090 \\
9,220 \\
1,148\end{array}$ & $\begin{array}{l}\mathbf{3 , 6 4 1} \\
\mathbf{5 , 4 3 4} \\
3,310 \\
\mathbf{8 , 2 7 6} \\
\mathbf{4 , 4 2 9} \\
\mathbf{4 , 3 3 8} \\
3,238 \\
\mathbf{0 , 4 9 3}\end{array}$ & $\begin{array}{r}11,7 \\
16,6 \\
6,9 \\
14,8 \\
17,2 \\
13,3 \\
6,9 \\
5,3\end{array}$ & $\begin{array}{l}\overline{ } \\
\bar{z} \\
\overline{\overline{100}} \\
{ }_{20}\end{array}$ & $\begin{array}{l}= \\
= \\
\overline{\overline{9}} \\
{ }_{92,5}\end{array}$ \\
\hline \multicolumn{8}{|c|}{ B. Titračná metóda - koféín } \\
\hline $\begin{array}{l}\text { Kofola } \\
\text { Coca-cola } \\
\text { Pepsi-cola }\end{array}$ & $\begin{array}{l}5 \\
5 \\
5\end{array}$ & $\begin{array}{c}63,70 \\
112,25 \\
68,2\end{array}$ & $\begin{array}{l}3,884 \\
7,768 \\
3,884\end{array}$ & $\begin{array}{l}1,670 \\
3,339 \\
1,670\end{array}$ & $\begin{array}{l}5,2 \\
5,9 \\
4,9\end{array}$ & $\bar{z}$ & $=$ \\
\hline \multicolumn{8}{|c|}{ C. Gravimetrická metóda - kofeín, teobromín } \\
\hline $\begin{array}{l}\text { Káva Santos } \\
\text { Káva Santos } \\
\text { + jot. príd. }\end{array}$ & & $\begin{array}{c}0,550 \\
1,525\end{array}$ & $\begin{array}{l}0,975 \\
0,975\end{array}$ & - & - & $\begin{array}{l}1,0 \\
1,0\end{array}$ & $\begin{array}{l}97,5 \\
97,5\end{array}$ \\
\hline
\end{tabular}

\section{Záver}

Zo štatistického zhodnotenia metód na stanovenie chinínu pre rutinnú kontrolu najpriaznivejšie vychádza fluorimetrická, ktorá je velmi citlivá, relatívne špecifická, dostatočne presná a pritom casove nenáročná trvanie analýzy niekolko minút. Vyžaduje vhodny fluorimeter, napr. Spekol s nástavcom. Vhodná čo do presnosti a správnosti je spektrofotometrická metóda s predchádzajúcou extrakciou. Je však menej citlivá (asi 10krát) a prácnejšia (jedno stanovenie s paralelkami trvá asi 1 hodinu). Vyžaduje sa spektrofotometer $s$ meraním absorbancie $v$ UV svetle. Titračné stanovenie chinínu je najmenej náročné na prístrojové vybavenie, je však náročné na čas ( 2 až 3 hodiny) a presnost. Aj citlivost je však nižšia než pri predchádzajúcich metódach. Priame spektrofotometrické meranie absorbancie je použitelné len na čisté roztoky, inak poskytuje vyššie hodnoty. 
Z preskúšaných metód na stanovenie kofeínu sa pre praktické účely ukázala vhodnejšia titračná metóda, ktorá je pomerne presná a časovo a prístrojovo menej náročná než fotometrická. Pre stanovenie teobromínu je možné použit gravimetrickú metódu, ktorá je pre praktické účely vyhovujúca.

Pre exaktnejšie výsledky uvedených alkaloidov najmä ak ide o zmesi - musí sa použif chromatografické rozdelenie.

\section{Literatúra}

[1] MEliChaR, B., a i.: Chemická léčiva, Avicenum, Praha 1972

[2] PRİBELA, A., TOMÁŠEK, K.: Zborník $s$ konferencie o nealkoholických nápojoch, Dom techniky, Košice 1977

[3] NOIJENS, J. M., VELDEN, H.: Z. Lebensmitt. Untersuch u. Forsch. 153,1973 , s. 97

[4] PN - GRT - Pivovary a sladovne, Praha 1974

[5] GILS, W. F., HIDSKES, G. G.: Z. Lebensmitt. Untersuch u. Forsch. 148, 1972, s. 89

[6] HADORN, H., ZÜRCHER, K.: Mitt Lebensm. Hyg. 55, 1964, s. 194

[7] HEY, H.: Z. Lebensmitt. Untersuch u. Forsch 148, 1972, s. 1

[8] BELJAARS, P. R., KOKEN, P. J.: J. ass. off. analyt. chem. 56, 1973. S. 1284

[9] BÄRWALD, G., PRUCHA, J.: Mineralwasser Z., 26, 1373, s. 859

[10] BANDION, F.: Mitt. Rebe u Wein, 25, 1975, s. 107

[11] WISNIEWSKI, J. V.: Helwett - Pacard applic. labor. report, 1001,1965

[12] RUICK, G.: Lebensm. Ind. 23, 1976, s. 131

[13] HADORN, H., ZÜRCHER, K.: Mitt. Geb. Lebensm. Hyg., 56, 1965. S. 491

[14] NEWTON, J. M.: J. ass. off. analyt. chem. 52, 1969, s. 1133

[15] LEHMANN, G., MORĀN, M.: Z. Lebensm. Untersuch. u. Forsch. 147, 1971 , s. 281

[16] I.UCCI, A., FERRAMONDO, A.: cit. z. Lebensm. Untersuch u. Forsch, 152, 1973, s. 217

[17] ČSN 580240 ONM, Praha 1964

[18] JAYRAMAN, K. S., RAMENUJAM, S.: Indian. J. Technol. 3, 1965, s. 337

[19] MEDOVARSKÁ, B.: Diplomová práca, CHTF, SVŠT, Bratislava 1976

[20] LEHMANN, G., NEUMANN, B.: z. Lebensm. Untersuch. u. Forsch. 133, 1373 , s. 363

[21] Čs. lékopis, Avicenum, Praha, 1970

[22] ČSN 580113 UNM, Praha 1970

[23] FRISCHKORN, C. G. B.: Z. Lebensm. Untersuch Forsch. 158, 1975, S. 295

[24] BALTES, W.: Z. Lebensm. Untersuch Forsch. 152, 1973, s. 145

[25] WITZHUM, O. G. a i.: Z. Lebensm. Untersuch. Forsch. 154, 1974, S. 135

[26] BALTES, W., KLASSMANN, M.: Z. Lebensm. Untersuch Forsch. 153, 1973 , s. 379

[27] FRANZKE, G. a i.: Z. Lebensm. Untersuch Forsch. 139, 1969, S. 85

[28] NOVÁKOVÃ, S.: Diplomová práca, CHTF, SVŠT, Bratislava, 1975

Príbela, A. - Tomášek, K. - Medovarská, B.: Stanovenie chinínu a kofeínu $v$ nealkoholických nápojoch. Kvas. prům. 24, 1978, č. 6, s. $135-137$.

Podla štatistického zhodnotenia je pre rutinní kontrolu obsahu chininu najvhodnejšia metoda fluorometrická, ktorá je velmi citlivá, relatívne špecifická, dostatoč- ne presná a velmi rýchla. Pre stanovenie kofeinu je vhodná titračná metoda, pomerne presná a časove menej náročná ako metoda fotometrická. Pre štanovenie teobrominu je použitelná gravimetrická metoda.

K získaniu exaktných výsledkov je nutné chromatografické rozdelenie.

Прибела, А. - Томашек, К. - Медоварска, Б.: Определение содержания хинина и кофеина в безалкогольных напитках. Квас. прум. 24, 1978 № 6, стр. 135-137.

Статистические данные показывают, что для контрольного определения содержания хинина в безалкогольных напитках следует в производственных условиях пользоваться флуорометрическим методом. Этот метод отличается высокой чувствительностью, дает достаточно точную информацию и экономит время. Для определения кофеина рекоментуется отдавать предпочтение титрированию. Анализ занимает меньше времени чем фото метрическое определение, обеспечивая одновременно достоверные данные. Теобромин определяется лучше всего с помощью всего анализа. Совершенно точные результаты может, однако, дать лишь разделилетьная хроматография.

Príbela, A. - Tomášek, K. - Medovarská, B.: Determination of Quinine and Caffeine in Non-alcoholic Beverages. Kvas. prům., 24, 1978, No. 6, pp. 135-137.

Statistical investigations confirm, that for routine determination of quinine, present in non-alcoholic beverages, the fluorometric method can be recommended as a very sensitive and specific one, giving reasonably accurate results and requiring little time. As far as the determination of caffeine is concerned, titration should be preferred to photometric method, since it provides more reliable data and saves time. Theobromine can be best determined by applying a gravimetric method. For exact results, it is, of course, necessary to use partition chromatography.

Príbela, A. - Tomášek, K. - Medovarská, B.: Bestimmung des Chinin- und Koffeingehalts in alkoholfreien Getränken. Kvas. prům., 24, 1978, No. 6, S. 135-137.

Nach der statistischen Auswertung eignet sich für die Routinkontrolle des Chiningehalts am besten die fluorimetrische Methode, die sehr empfindlich, relativ spezifisch, genügend genau und sehr schnell ist. Für die Koffeinbestimmung ist die Titrationsmethode geeignet, denn sie ist verhältnismäßig genau und im Vergleich mit der photometrischen Methode weniger zeitraubend. Für die Bestimmung des Teobromins wird die gravimetrische Methode empfohlen. Für Erzielung exakter Ergebnisse ist die chromatographische Trennung notwendig. 